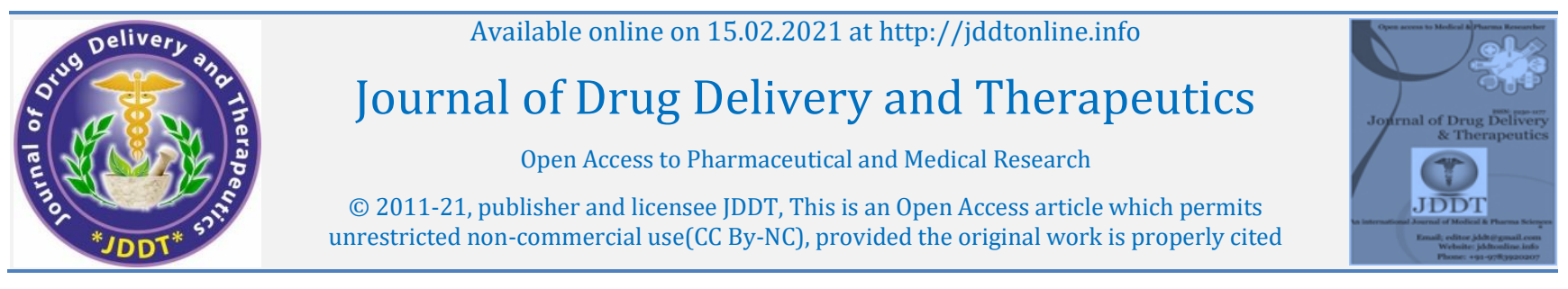

\title{
Efficacy and Safety of 5-Hydroxytryptamine-3 Receptor Antagonists (5- HT3 RAs) for The Prevention of Chemotherapy-Induced Nausea and Vomiting in Cancer Patients: A Review
}

\author{
Nisaurrahmah Nisaurrahmah, Oktavia Sri, and Ifora Ifora* \\ Department of Pharmacology and Clinical Pharmacy, School of Pharmaceutical Science Padang (STIFARM PADANG), West Sumatera, Indonesia,
} 25147

\begin{tabular}{l}
\hline Article Info: \\
\hline Article History: \\
Received 11 Dec 2020; \\
Review Completed 26 Jan 2021 \\
Accepted 04 Feb 2021; \\
Available online 15 Feb 2021
\end{tabular}

\section{*Address for Correspondence:}

Oktavia Sri, and Ifora Ifora, Department of Pharmacology and Clinical Pharmacy, School of Pharmaceutical Science Padang (STIFARM PADANG), West Sumatera, Indonesia, 25147

\section{Cite this article as:}

Nisaurrahmah N, Sri O, Ifora I, Efficacy and Safety of 5-Hydroxytryptamine-3 Receptor Antagonists (5HT3 RAs) for The Prevention of ChemotherapyInduced Nausea and Vomiting in Cancer Patients: A Review, Journal of Drug Delivery and Therapeutics. 2021; 11(1-s):57-61

DOI: http://dx.doi.org/10.22270/jddt.v11i1-s.4554

\section{Abstract}

Objective: This review provides an update review of the efficacy and safety of 5hydroxytryptamine-3 receptor antagonists in the prevention of chemotherapy-induced nausea and vomiting (CINV) in cancer patients.

Methods: The information was collected from electronic scientific search engines from PubMed, Science Direct, Scopus, and Google Scholar. The publication dates covered were from 2010 to 2020. The primary endpoint was the percentage of patients who achieved a complete response (CR), complete control (CC), no nausea, no emesis, or no rescue medication.The secondary endpoint was the percentage of patients who experience constipation related to 5-HT RA constipation, headache, diarrhea, or dizziness, as well as changes in heart rhythm.

Results: Fourteen articles were identified. Palonosetron has the same effectiveness as granisetron as but more effective than ondansetron in the delayed phase and overall. Adverse effects that often occur due to the use of palonosetron, granisetron, and ondansetron are constipation and headache. Some of the articles also mentioned that palonosetron does not cause changes in heart rhythm but granisetron and ondansetron do cause changes in the electrocardiogram (ECG) at certain doses.

Conclusion: Palonosetron has the same effectiveness as granisetron, and more effective than ondansetron in delayed, and overall phases. The use of palonosetron, granisetron, and ondansetron cause constipation and headaches at all doses, palonosetron does not cause ECG abnormalities whereas granisetron and ondansetron cause ECG changes.

Keywords: palonosetron, ondansetron, granisetron, 5- $\mathrm{HT}_{3} \mathrm{RAs}$, cancer, nausea, vomiting, CINV.

\section{INTRODUCTION}

Chemotherapy-induced nausea and vomiting (CINV) refers to the adverse effects of vomiting associated with the use of drugs used to treat cancer. Acute CINV is nausea and vomiting starting within a few minutes to a few hours after receiving chemotherapy, delayed phase CINV is nausea and vomiting starts or returns 24 hours or more after receiving chemotherapy. CINV is most likely the result of chemotherapy that works in two places: directly in the gastrointestinal tract and in vomiting brain cancer. In both areas, nausea and vomiting are mediated by the action of certain neurotransmitters, with dopamine, neurokinin-1, and serotonin being the most important. ${ }^{1}$.

Research conducted by Chatterjee et al., 2014 looked at side effects in lung cancer (44\%), and head and neck (12\%), as many as 50 patients used platinum class drugs. Research data stated that the occurrence of alopecia (96\%), nausea (90\%), anemia (90\%), vomiting (82\%), paresthesia (54\%), stomatitis (38\%), diarrhea (38\%) and autotoxicity (26\%) ${ }^{2}$.
High emetogenic chemotherapy (HEC) and moderate emetogenic chemotherapy (MEC) chemotherapy regimens have a negative impact and affect the quality of life of patients, both moderate and even after chemotherapy, namely in the delayed phase, nausea has a stronger negative impact on the quality of life than vomiting ${ }^{3}$.

Guidelines that can be used to control the occurrence of CINV are the national comprehensive cancer network (NCCN), the American society of clinical oncology (ASCO), and the multinational association of supportive care in cancer (MASCC). The therapy used to treat CINV is the use of antiemetic drugs from the 5-HT3 receptor antagonists, dexamethasone, NK1 receptor antagonists, and olanzapine groups 4. Emetic risk (if no prophylactic medication is administered) are high emetogenic chemotherapies (HEC), moderate emetogenic chemotherapies (MEC), low emetogenic chemotherapies (LEC) ${ }^{5}$. Preventing CINV is better than treating CINV ${ }^{6}$. 
The efficacy and safety of the drug were evaluated by preclinical animal toxicology, pathology, and safety pharmacology studies followed by staged clinical trials in humans (i.e. phases I, II, III, and post-marketing surveillance) 7. The efficacy and safety of the drug are very important to be evaluated after the drug is marketed to achieve the expected efficacy with tolerable side effects. 5-Hydroxytryptamine-3 Receptor Antagonists are antiemetic drugs that are often used and are always recommended for HEC and MEC patients in both acute and delayed phases. This review describes how the efficacy and safety of the 5hydroxytryptamine-3 receptor antagonists class of drugs after use in patients, especially patients receiving chemotherapy to prevent nausea and vomiting so that patients are comfortable in chemotherapy and improve patient quality of life during and after chemotherapy.

\section{METHOD}

All relevant literature databases were searched from 2010 to 2020. We searched the following electronic databases: PubMed, Science Direct, Scopus, and Google Scholar. The keywords were "efficacy", safety","adverse drug effect", "adverse drug reaction", "adverse drug event". "Toxicity", "5Hydroxytryptamine-3 receptor antagonists", "palonosetron", "ondansetron", "granisetron", "dolasetron", "cancer", "chemotherapy" he inclusion criteria included in this review were articles reporting drug efficacy or safety 5Hydroxytryptamine- 3 receptor antagonists. Animal studies and case reports are excluded.

The indicator to assess the efficacy of this study ware the percentage of patients achieving either a Complete Response (CR) and complete control (CC). CR was defined as no vomiting episode without the use of rescue medication for the entire study period, and CC was defined as no vomiting episode, no need for rescue medication, and no more than mild nausea. Meanwhile, indicators to assess safety included the percentage of patients suffering from RA 5-HT-related headache, constipation, diarrhea, or dizziness, as well as changes in heart rhythm.

\section{RESULT AND DISCUSSION}

14 eligible articles were identified. 3 articles reported the efficacy, 5 articles reported the safety, and 6 articles reported the efficacy and safety of the antiemetic $5 \mathrm{HT}_{3} \mathrm{RAs}$ alone.

\section{EFFICACY}

\section{Palonosetron}

A study by Saito et al. reported the use of $0.75 \mathrm{mg}$ of intravenous palonosetron on non-Hodgkin's lymphoma patients and showed that in the 1st cycle, the CR was $92.5 \%$ in the acute phase, $85 \%$ in the delayed phase, $85 \%$ in the overall phase, while the CC was $82.5 \%$ in the acute phase, $70 \%$ in the acute and delayed phase, and $62.5 \%$ in the total phase. For the $2^{\text {nd }}$ cycle, the CR was $95 \%$ in the acute phase, $95 \%$ in the delayed phase, $92.5 \%$ in the overall phase while CC was $85 \%$ in the acute phase, $85 \%$ in the delayed phase, and $80 \%$ in the overall phase ${ }^{8}$.

Another study used $0.25,0.50$, and $0.75 \mathrm{mg}$ of palonosetron or $0.25 \mathrm{mg}$ of palonosetron intravenously on breast, colon, lung cancer patients. The results showed that $0.25 \mathrm{mg}$ oral palonosetron achieved CR of $70.1 \%$ in acute phase, $61.0 \%$ in delayed phase, and $54.5 \%$ in the overall phase. The CR of $0.50 \mathrm{mg}$ of palonosetron given orally showed $66.7 \%$ in the acute phase, $61.7 \%$ in the delayed phase, and $54.3 \%$ in the overall phase. The CR of $0.75 \mathrm{mg}$ of palonosetron given orally was $62.8 \%$ in the acute phase, $56.4 \%$ in the delayed phase, and $47.4 \%$ in the overall phase. The CR of palonosetron 0.25 mg i.v. was $57.5 \%$ in the acute phase, $62.5 \%$ in the delayed phase, and $52.5 \%$ in the overall phase ${ }^{9}$.

Palonosetron $0.75 \mathrm{mg}$ i.v. showed that CR was not significantly different between cycle one and cycle two in the acute phase, this result proved that palonosetron had the same effectiveness both in cycle one and cycle two during the acute phase. The percentage of CC $(p=0.054)$ tended to increase, and CR ( $p=0.019)$ increased significantly, the percentage was increased by $15 \%$ in the delayed phase of cycle one. This result indicated that palonosetron is more effective when used in the delayed phase. In the overall phase, the palonosetron reached CR ( $p=0.002)$, and CC ( $p=$ 0.002 ) increased significantly after cycle two. Based on the CR and CC results achieved, palonosetron is very effective in controlling CINV in the delayed phase after cycle two. Palonosetron is more effective in cycle 2 than cycle 1 because Saito et al.'s study was conducted on malignant lymphoma cancer patients. This cancer responded better than other solid cancers and tumor volume decreased significantly after the first cycle of $\mathrm{CHOP}$.

Boccia et al. compared three doses of oral palonosetron and one dose of intravenous palonosetron. The oral route of 0.25 , 0.50 , and $0.75 \mathrm{mg}$ palonosetron was as effective as the intravenous route of palonosetron $0.25 \mathrm{mg}$. This study also compared the effectiveness of three doses of oral palonosetron, i.e., $0.25,0.50$, and $0.75 \mathrm{mg}$, and showed good efficacy in controlling CINV. Of the three doses of palonosetron, the oral $0.50 \mathrm{mg}$ was numerically more effective than other doses. Oral palonosetron $0.50 \mathrm{mg}$ is the preferred therapy option ${ }^{9}$.

\section{Ondansetron}

A study on glioma patients treated CINV with ondansetron 8 mg for 1-5 days. The results showed that the primary results obtained a CC of $54.5 \%$, while the secondary results obtained CR of $87.9 \%$ in acute phase and $57.6 \%$ in the delayed phase. Ondansetron $8 \mathrm{mg}$ alone given for 5 days after chemotherapy was not optimal for treating nausea and vomiting in glioma cancer patients, especially in the delayed phase. Ondansetron alone could not control CINV well in glioma cancer because glioma cancer has several episodes of vomiting. Thus, it was a little difficult to control using only a single antiemetic ${ }^{10}$.

\section{Palonosetron versus Granisetron}

Tian et al. reported Palonosetron or granisetron use in lung, breast, colorectal, and gastric cancer patients. The study showed that a complete response of $71.09 \%$ occurred in the acute phase, $60.16 \%$ in the delayed phase, and $53.13 \%$ in the overall phase for palonosetron, while the granisetron was $65.22 \%$ in the acute phase, $55.80 \%$ in the delayed phase, and $50.00 \%$ in the overall phase 11 .

Another study on acute myeloid leukemia cancer used cytarabine $\left(100-200 \mathrm{mg} / \mathrm{m}^{2}\right)$, a regimen of anthracycline (idarubicin $12 \mathrm{mg} / \mathrm{m}^{2}$, daunorubicin $50 \mathrm{mg} / \mathrm{m}^{2}$, aclarubicin $20 \mathrm{mg} / \mathrm{m}^{2}$, and $7 \mathrm{mg} / \mathrm{m}^{2}$ ) with antiemetic granisetron $3 \mathrm{mg}$ or palonosetron $0.75 \mathrm{mg}$. The results showed that in the acute phase, The CC of palonosetron was $70 \%$ and $83 \%$ in the delayed phase. Meanwhile, granisetron showed CC of $39 \%$ in the acute phase, and $57 \%$ in the delayed phase 12 .

A study on Hodgkin's lymphoma patients investigated Adriamycin $\left(25 \mathrm{mg} / \mathrm{m}^{2}\right)$, bleomycin $\left(10 \mathrm{mg} / \mathrm{m}^{2}\right.$ to $15 \mathrm{mg} / \mathrm{kg}$ $\mathrm{BW})$, vinblastine $\left(6 \mathrm{mg} / \mathrm{m}^{2}\right.$ to $\left.10 \mathrm{mg} / \mathrm{kg} \mathrm{BW}\right)$, and dacarbazine. Antiemetics used were granisetron $(3 \mathrm{mg} / \mathrm{kg}$ BW) or palonosetron $(0.75 \mathrm{mg} / \mathrm{kg} \mathrm{BW})$. This study found $33.3 \%$ of CC in the acute phase of palonosetron and $44.4 \%$ in 
the delayed phase. The CC in the acute phase, delayed phase, and overall phase of granisetron was $16.7 \%, 38.1 \%$, and $33.3 \%$, respectively 13 .

A study conducted on a Chinese patient population showed higher CR palonosetron results than granisetron in the acute $(\mathrm{P}=0.28)$, delayed $(\mathrm{P}=0.46)$, and overall $(\mathrm{P}=0.61)$ phase, but this difference was not statistically significant. The same CR results also stated that palonosetron and granisetron have the same efficacy in controlling CINV MEC and HEC in the acute, delayed, and overall phase in patients with lung cancer, breast cancer, colorectal cancer, and gastric cancer 11 .

Similarly, another study was carried out on the Japanese population. This study showed a significant difference between CC of palonosetron and granisetron in the acute phase $(\mathrm{P}=0.0458)$, while for the delayed phase $(\mathrm{P}=0.0653)$, there was no significant difference between palonosetron and granisetron even though the number of patients achieving CR was higher in palonosetron. Based on CC, palonosetron is more efficacious in the acute phase and has the same efficacy as granisetron in the delayed phase in preventing CINV Japanese hematological cancer 12 .

Other studies have been conducted on different cancers. Research data showed that CC was not significantly different between palonosetron and granisetron in the acute, delayed, and overall phases. Palonosetron and granisetron alone showed similar efficacy and can be used to control the occurrence of CINV caused by chemotherapy regimens, such as adriamycin, bleomycin, vinblastine, and dacarbazine in Hodgkin's lymphoma cancer ${ }^{13}$.

\section{Palonosetron versus Ondansetron}

Parathoduvil et al. reported that intravenous palonosetron $0.25 \mathrm{mg}$ or intravenous ondansetron $8 \mathrm{mg}$ on cancer patients showed that the CR of palonosetron in the acute phase was $89.6 \%$, in the delayed phase was $86.8 \%$, and in the overall phase was $82.1 \%$. Meanwhile, ondansetron showed $80.2 \%$ in the acute phase, $70.8 \%$ in the delayed phase, and $65.1 \%$ in the overall phase. Palonosetron statistical data were significant compared to ondansetron in the delayed phase $(p$-value $=0.006)$ and the overall phase $(p$-value $=0.008)$ These results indicated that a single intravenous palonosetron $0.25 \mathrm{mg}$ in the Indian population is clinically more effective than a single intravenous ondansetron $8 \mathrm{mg}$ in the delayed and overall phase 14 .

Additionally, a randomized study in acute myelogenous leukemia patients with a regimen containing cytarabine (cytarabine plus idarubicin [12 $\mathrm{g} / \mathrm{m}^{2}$ for 3 days excluded] and cytarabine plus fludarabine $\left[30 \mathrm{~g} / \mathrm{m}^{2}\right.$ for 5 days]), using the antiemetics of Ondansetron $8 \mathrm{mg}$, palonosetron $0.25 \mathrm{mg}$ i.v. day $1-5$, palonosetron $0.25 \mathrm{mg}$ i.v. day $1,3,5$ was conducted. The study showed that the complete response achieved in palonosetron $1-5$ was $31 \%$, palonosetron $1,3,5$ was $35 \%$, and ondansetron $21 \% 15$.

Palonosetron alone showed higher CR but not significantly different compared to ondansetron. There were $>77 \%$ of patients who did not experience nausea on day 1 , with a decreased percentage on day 2 to 5 , and a significant increase on day 6 and 7 after receiving palonosetron. Patients did not vomit more after day 1. Palonosetron and ondansetron were effective in controlling CINV on day 1 and less effective on days 2-5. Administration of palonosetron on day 4 or 5 can significantly reduce vomiting on day 6 and 7 . Palonosetron was less effective on days 2-5 because of the overlapping emetogenic effects of 2 chemotherapy agents on those days ${ }^{15}$.

\section{First-Generation versus Second-Generation 5-HT3 RAs}

A study on breast cancer and lung cancer using carboplatin or cisplatin-based chemotherapy, cyclophosphamide, and other antiemetics of palonosetron or RA 5-HT3 was conducted. The results showed that the $\mathrm{CR}$ of palonosetron reached $46.1 \%$ while other RA 5-HT3 reached $41.3 \%$ in breast cancer. The CR of palonosetron was $72.9 \%$ while other RA 5-HT3 was $63.4 \%$ in carboplatin-treated lung cancer. The CR of palonosetron was $51.0 \%$ while another 5 HT3 RA was $45.6 \%$ in lung cancers treated with cisplatin 16 .

The clinical efficacy of palonosetron was associated with hospital and emergency department visits in real-world practice, where palonosetron alone is significant compared to other $5-\mathrm{HT}_{3} \mathrm{RAs}(\mathrm{p}<0.0001)$ in breast cancer patients. The statistical results of palonosetron were also significant $(\mathrm{p}<$ 0.0001) in lung cancer patients on the carboplatin chemotherapy regimen. These data proved that a palonosetron alone was more effective than other $5-\mathrm{HT}_{3} \mathrm{RAs}$ in controlling nausea and vomiting in lung and breast cancer patients using the chemotherapy drug carboplatin. Different results were shown by palonosetron in controlling nausea and vomiting in lung cancer patients using cisplatin, where palonosetron alone was not significant $(p=0.1170)$ but more patients were free from nausea and vomiting on palonosetron than other $5-\mathrm{HT}_{3}$ RAs ${ }^{16}$.

Nine articles discussed that the use of palonosetron, granisetron, and ondansetron alone have good efficacy in controlling CINV in the acute phase, the delayed phase, and overall phase because these 5-HT3RA class drugs have a strong binding power to 5-HT3 receptors. Palonosetron has a longer half-life than granisetron and ondansetron so that it can better control CINV in the delayed phase ${ }^{17}$.

\section{SAFETY}

Class 5-HT3RA drugs have peripheral receptors in the intestines and centers, namely the chemoreceptor trigger zone (CTZ) 18. Constipation, headaches, and changes in heart rhythm were side effects reported as a result of using 5-HT3 RA in the NCCN guidelines ${ }^{19}$. Eleven studies reported several adverse effects.

\section{Constipation and headaches}

\section{Palonosetron}

Mattuizzi et al. conducted a study using a randomized method which stated that the severity of constipation and headaches experienced by patients using palonosetron occurred at levels 1-3 according to the NCI, but there was 1 patient who used palonosetron on days 1-5 and experienced a level 3 headache ${ }^{15}$. In Japanese patients diagnosed with Hodgkin's lymphoma cancer who were given palonosetron $0.75 \mathrm{mg}$, it was found that $27.8 \%$ of patients had constipation 13.

A previous study by Tian et al. showed that Chinese patients diagnosed with lung cancer, breast cancer, rectal colon cancer, and gastric cancer showed adverse effects from palonosetron $0.25 \mathrm{mg}$ i.v. bolus, namely constipation $8,59 \%$, and headache $6.25 \%{ }^{11}$. In a study with the same dose of palonosetron but different methods of administration in all types of cancer, intravenous use of palonosetron $0.25 \mathrm{mg}$ caused $4.7 \%$ constipation and $9.4 \%$ headache in South Indian patients 14 .

Boccia et al. reported that the most common side effects were constipation and headache. Constipation was reported by $3.1 \%$ of patients on $0.25 \mathrm{mg}$ of i.v. palonosetron, $0.6 \%$ on $0.25 \mathrm{mg}$ of oral palonosetron and $0.50 \mathrm{mg}$, and $3.2 \%$ of 
patients on $0.75 \mathrm{mg}$ of oral palonosetron. Headaches were reported after receiving palonosetron $0.25 \mathrm{mg}$ with $3.8 \%$, $0.50 \mathrm{mg}$ with $3.7 \%, 0.75 \mathrm{mg}$ with $3.8 \%$ and slightly increased on palonosetron $0.25 \mathrm{mg}$ iv with $8.6 \%{ }^{9}$.

\section{Granisetron}

The use of granisetron $3 \mathrm{mg}$ in Japan caused constipation side effects in $9.5 \%$ of patients, whereas headache was reported in $11.1 \% 13$. A different study conducted in a Chinese population using granisetron $3 \mathrm{mg}$ i.v. bolus. This study showed that constipation side effects occurred in $8.70 \%$ of patients, while headache occurred in $5.80 \%$ of patients 11 .

\section{Ondansetron}

The common side effects of ondansetron $8 \mathrm{mg}$ reported were grade 1-3 constipation and headache based on the NCI 15. A study by Petel et al. showed that patients with glioma cancer have experienced an incidence of $11 \%$ constipation and $6 \%$ headache when using ondansetron $8 \mathrm{mg}$ for 5 days 10. Additionally, intravenous use of ondansetron $8 \mathrm{mg}$ showed constipation in $8.5 \%$ of patients and headache in $17 \%{ }^{14}$.

\section{First-generation versus the second-generation 5-HT3 RAs}

The constipation side effect was more due to the use of palonosetron $0.25 \mathrm{mg}$ i.v. compared to granisetron $3 \mathrm{mg}$ i.v. bolus 11. Different doses also showed the same result, whereas palonosetron $0.75 \mathrm{mg}$ caused more frequent constipation than granisetron $3 \mathrm{mg}$ 13. Constipation experienced by patients using ondansetron $8 \mathrm{mg}$ i.v. was higher than in patients using palonosetron $0.25 \mathrm{mg}$ i.v. ${ }^{14}$.

\section{Cardiac Adverse Effect}

\section{Palonosetron}

Gonullu et al. demonstrated that palonosetron did not cause severe rhythm disturbances or symptomatic ECG changes. Palonosetron is safe to administer as an antiemetic for cancer patients 20 .

In other studies, the average heart rate did not differ among the 76 patients who were enrolled before and after administration of palonosetron $(p=0.6)$. Systolic and diastolic blood pressures were not significantly different before and after palonosetron ( $\mathrm{p}$ values 0.9 and 0.3 , respectively). Although the median QT min value was higher after palonosetron administration than before palonosetron administration, the difference was not statistically significant $(p=0.6)$. Palonosetron did not show to have an acute arrhythmogenic potential 21 .

A study used a randomized palonosetron $0.25 \mathrm{mg}$ i.v. on day $1-5$, palonosetron $0.25 \mathrm{mg}$ iv on day $1,3,5$ and found no abnormalities in the heart 15. Additionally, another study reported that although abnormal ECG records were observed in $7.81 \%(10 / 128)$ of palonosetron treatments, only one abnormal ECG finding was assessed as possibly related to the drug studied (palonosetron). In conclusion, the study demonstrated that a single i.v. dose of palonosetron $0.25 \mathrm{mg}$ was safe and effective to prevent CINV 11.

\section{Granisetron}

A total of 16 patients were treated with carboplatin weekly consecutively. There was bradycardia in patients who obtain granisetron $40 \mu \mathrm{g} / \mathrm{kg}$ and the PR interval was shortened in patients who received granisetron at a dose of $10 \mu \mathrm{g} / \mathrm{kg}(\mathrm{p}=$ 0.021). QTc interval and dispersion were found to be similar between both doses of granisetron ${ }^{22}$. Different results in adult patients with the new granisetron formulation, namely APF530 1-gram SC did not cause significant changes in QTcF. The maximum observed QTcF change was $4.15 \mathrm{~ms}(90 \% \mathrm{CI}$, 0.94 to 7.36 ) at 3 hours. There were no clinically significant changes on other electrocardiograms ${ }^{23}$.

\section{Ondansetron}

A study in cancer patients receiving the antiemetic ondansetron IV suggests that IV doses of ondansetron $8 \mathrm{mg}$ (direct observations) and $16 \mathrm{mg}$ (simulation) delivered over 15 minutes were not expected to produce clinically important QTc prolongations, while $24 \mathrm{mg}$ (simulation) and $32 \mathrm{mg}$ (direct observations) IV doses may induce clinically important QT prolongations and may represent an increased risk that exceeds benefit 24 . In another study on glioma cancer patients, ondansetron $8 \mathrm{mg}$ did not cause an increase in ST and only one mild cardiac toxicity (atrial fibrillation) 10. Additionally, patients using the antiemetic ondansetron $8 \mathrm{mg}$ found no abnormalities in the heart 15 .

\section{Other Adverse Effects}

Tian et al., reported other adverse effects from intravenous $0.25 \mathrm{mg}$ palonosetron, $12.5 \%$ of which was leukopenia, $10.16 \%$ fatigue, $7.81 \%$ alanine aminotransferase or aspartate aminotransferase, $7.03 \%$ dizziness, $4.69 \%$ anemia, and $0.78 \%$ thrombocytopenia 11 . A study reported that palonosetron $0.75 \mathrm{mg}$ resulted in $100 \%$ anorexia, $72.2 \%$ malaise, $66.7 \%$ leucopenia, $66.7 \%$ neutropenia, $33.3 \%$ fever, $16.7 \%$ oral mucositis, $0 \%$ febrile neutropenia, $0 \%$ neuropathy, and $0 \%$ diarrhea ${ }^{13}$.

Other adverse effects were also found when using granisetron $3 \mathrm{mg}$ i.v. bolus included $15.94 \%$ leukopenia, $9.42 \%$ fatigue, $6.52 \%$ alanine aminotransferase or aspartate aminotransferase, $10.87 \%$ dizziness, $6.52 \%$ anemia, and $6.52 \%$ thrombocytopenia 11 . Different results were reported by patients who used granisetron $3 \mathrm{mg}$ i.v. causing $71.4 \%$ anorexia, $38.1 \%$ malaise, $19.1 \%$ leucopenia, $14.3 \%$ neutropenia, $14.3 \%$ fever, $14.3 \%$ oral mucositis, $14.3 \%$ febrile neutropenia, 9.5\% neuropathy, and 9.5\% diarrhea 13 .

Other adverse effects were also reported by patients who used ondansetron $8 \mathrm{mg}$, in addition to constipation, headache, and other adverse effects reported in the study were categorized as mild/moderate, other common adverse effects showed in the study were $11 \%$ anorexia and $20 \%$ fatigue ${ }^{10}$. Uchida et al. and Petel et al. reported that anorexia was the other adverse effect, which was the highest. Different results by Tian et al. reported that the side effect of leukopenia was the highest reported by patients.

The adverse effects of anorexia and leukopenia were side effects caused by the chemotherapy regimen, not by the antiemetics used by the patient. Drach et al. stated that rituximab, cyclophosphamide, doxorubicin, and prednisone plus bortezomib (VR-CAP) or vincristine (RCHOP) caused neutropenia (92 vs $76 \%$ ), thrombocytopenia (70 vs $10 \%$ ), leukopenia (65 vs. $50 \%$ ), anemia ( 46 vs. $40 \%$ ), pyrexia ( 41 vs. $14 \%$ ), lymphopenia ( 32 vs. $14 \%$ ) and peripheral sensory neuropathy (each 24\%) 25.

The association between 5-HT3 antagonists' receptors with their receptors affected the central nervous system, peripheral nervous system, and immune response 26 . Also, differences in pharmacological and pharmacokinetic properties in the use of antiemetics cause different percentages of adverse drug reactions. The percentage of patients who experienced adverse drug reactions occurs due to the different levels of binding power between the two 
antiemetics with the receptors and the elimination half-life 27.

\section{CONCLUSION}

We conclude that palonosetron is effective in controlling the occurrence of CINV in the acute, delayed, and overall phases. Palonosetron is almost as effective as granisetron and is more effective than ondansetron in the delayed and overall phases. The most commonly reported adverse effects are constipation and headaches. Constipation and headache were more often experienced in patients taking palonosetron but palonosetron was safer in terms of cardiac-related adverse effects than granisetron and ondansetron.

\section{CONFLICT OF INTEREST}

The authors declare that they have no conflicts of interest.

\section{REFERENCES}

1. Ferri FF. Ferri's Clinical Advisor: 5 Books 1. Pliladelphia: Elsevier; 2019. 308 p.

2. Chatterjee D, Roy S, Hazra A, Dasgupta P, Ganguly S, Das AK. Variation of adverse drug reaction profile of platinum-based chemotherapy with body mass index in patients with solid tumors: An observational study. Indian J Pharmacol. 2014; 46(2):222-4.

3. Bloechl-Daum B, Deuson RR, Mavros P, Hansen M, Herrstedt J. Delayed nausea and vomiting continue to reduce patients' quality of life after highly and moderately emetogenic chemotherapy despite antiemetic treatment. J Clin Oncol. 2006; 24(27):4472-8.

4. Razvi Y, Chan S, McFarlane T, McKenzie E, Zaki P, DeAngelis C, et al. ASCO, NCCN, MASCC/ESMO: a comparison of antiemetic guidelines for the treatment of chemotherapy-induced nausea and vomiting in adult patients. Support Care Cancer. 2019; 27(1):87-95.

5. Berryman LY. Pharmacotherapy Handbook. 2nd Edition. Vol. 34, The Annals of Pharmacotherapy. 2000; 1490-1490 p.

6. Feinberg B, Gilmore J, Haislip S, Jackson J, Jain G, Balu S, et al. Impact of initiating antiemetic prophylaxis with palonosetron versus ondansetron on risk of uncontrolled chemotherapyinduced nausea and vomiting in patients with lung cancer receiving multi-day chemotherapy. Support Care Cancer. 2012; 20(3):615-23.

7. Ekins S, Xu JJ. Drug Efficacy, Safety, and Biologics Discovery. Canada: Wiley; 2009. 4 p.

8. Saito B, Nakashima H, Abe M, Murai S, Baba Y, Arai N, et al. Efficacy of palonosetron to prevent delayed nausea and vomiting in non-Hodgkin's lymphoma patients undergoing repeated cycles of the CHOP regimen. Support Care Cancer. 2018; 26(1):269-74.

9. Boccia R, Grunberg S, Franco-Gonzales E, Rubenstein E, Voisin D. Efficacy of oral palonosetron compared to intravenous palonosetron for the prevention of chemotherapy-induced nausea and vomiting associated with moderately emetogenic chemotherapy: A phase 3 trial. Support Care Cancer. 2013; 21(5):1453-60.

10. Patel MP, Woodring S, Randazzo DM, Friedman HS, Desjardins A Healy P, et al. Response to the letter to the "Randomized openlabel phase II trial of 5-day aprepitant plus ondansetron compared to ondansetron alone in the prevention of chemotherapy-induced nausea-vomiting (CINV) in glioma patients receiving adjuvant temozolomide." Support Care Cancer. 2020; 28(12):5591-2.

11. Tian W, Wang Z, Zhou J, Zhang S, Wang J, Chen Q, et al. Randomized, double-blind, crossover study of palonosetron compared with granisetron for the prevention of chemotherapy- induced nausea and vomiting in a Chinese population. Med Oncol. 2011; 28(1):71-8.

12. Matsumaru A, Tsutsumi Y, Ito S. Comparative investigation of the anti-emetic effects of granisetron and palonosetron during the treatment of acute myeloid leukemia. Mol Clin Oncol. 2017; $7(4): 629-32$.

13. Uchida M, Nakamura T, Hata K, Watanabe H, Mori Y, Kato K, et al. Antiemetic efficacy and safety of granisetron or palonosetron alone and in combination with a corticosteroid for ABVD therapy-induced nausea and vomiting. J Pharm Heal Care Sci. 2018; 4(1):1-7.

14. Parathoduvil AA, Sisupalan A, Rema PL. Comparison of antiemetic effectiveness of palonosetron versus ondansetron in patients on cancer chemotherapy: A prospective observational study in south Indians. J Clin Diagnostic Res. 2017; 11(5):FC104.

15. Mattiuzzi GN, Cortes JE, Blamble DA, Bekele BN, Xiao L, Cabanillas $\mathrm{M}$, et al. Daily palonosetron is superior to ondansetron in the prevention of delayed chemotherapyinduced nausea and vomiting in patients with acute myelogenous leukemia. Cancer. 2010; 116(24):5659-66.

16. Hatoum HT, Lin SJ, Buchner D, Cox D. Comparative clinical effectiveness of various 5-HT3 RA antiemetic regimens on chemotherapy-induced nausea and vomiting associated with hospital and emergency department visits in real world practice. Support Care Cancer. 2012; 20(5):941-9.

17. Grunberg SM, Koeller JM. Palonosetron: A unique 5-HT3 receptor antagonist for the prevention of chemotherapy-induced emesis. Expert Opin Pharmacother. 2003; 4(12):2297-303.

18. Smith P, Lavery A, Turkington RC. An overview of acute gastrointestinal side effects of systemic anti-cancer therapy and their management. Best Pract Res Clin Gastroenterol. 2020; 4849:101691.

19. Clinical N, Guidelines P, Guidelines N. Antiemesis. 2019;

20. Gonullu G, Demircan S, Demirag MK, Erdem D, Yucel I. Electrocardiographic findings of palonosetron in cancer patients. Support Care Cancer. 2012; 20(7):1435-9.

21. Yavas C, Dogan U, Yavas G, Araz M, Yavas Ata O. Acute effect of palonosetron on electrocardiographic parameters in cancer patients: A prospective study. Support Care Cancer. 2012; 20(10):2343-7.

22. Cakir FB, Yapar O, Canpolat C, Akalin F, Berrak SG. Cardiac effects of granisetron in a prospective crossover randomized dose comparison trial. Support Care Cancer. 2012; 20(10):24517.

23. Mason JW, Moon TE, O’Boyle E, Dietz A. Arandomized, placebocontrolled, four-period crossover, definitive QT study of the effects of APF530 exposure, high-dose intravenous granisetron, and moxifloxacin on QTc prolongation. Cancer Manag Res. 2014; 6(1):181-90.

24. Zuo P, Haberer LJ, Fang L, Hunt TL, Ridgway D, Russo MW. Integration of modeling and simulation to support changes to ondansetron dosing following a randomized, double-blind, placebo-, and active-controlled thorough QT study. J Clin Pharmacol. 2014; 54(11):1221-9.

25. Drach J, Huang H, Samoilova O, Belch A, Farber C, Bosly A, et al. Efficacy and safety of frontline rituximab, cyclophosphamide, doxorubicin and prednisone plus bortezomib (VR-CAP) or vincristine (R-CHOP) in a subset of newly diagnosed mantle cell lymphoma patients medically eligible for transplantation in the randomized. Leuk Lymphoma. 2018; 59(4):896-903.

26. Shajib MS, Khan WI. The role of serotonin and its receptors in activation of immune responses and inflammation. Acta Physiol. 2015; 213(3):561-74.

27. Maemondo M, Masuda N, Sekine I, Kubota K, Segawa Y, Shibuya $\mathrm{M}$, et al. A phase II study of palonosetron combined with dexamethasone to prevent nausea and vomiting induced by highly emetogenic chemotherapy. Ann Oncol. 2009; 20(11):1860-6. 